\title{
ANALISIS KEPEMIMPINAN, KOMPENSASI TERHADAP KINERJA GURU DAN DISIPLIN KERJA SEBAGAI VARIABEL INTERVENING DI SMA/SMK YADIKA TANJUNG DUREN JAKARTA
}

\author{
Edi Siregar \\ Program Studi Manajemen Fakultas Ekonomi Universitas Satya Negara Indonesia Jakarta \\ edisiregarusni@gmail.com
}

\begin{abstract}
This research aims to know the influence of leadership, compensation on performance through work discipline as an intervening variable. The object of this research is the SMA/SMK Yadika Tanjung Duren Jakarta with 85 of respondents. data analysis is the analysis of the path and processed with SPSS program Version 22. Sampling method using quota Sampling is by examining the census or the population.

The results of this study showed that there was no direct influence leadership against the discipline of work, there is a direct positive influence compensation against a work discipline, and there is the influence of the leadership and work discipline against compensation, there is a direct influence on the discipline of work on performance of teachers, teachers, performance against the leadership and direct influence negative compensation on performance of teachers.
\end{abstract}

Keywords: leadership, compensation, performance and work discipline.

\section{PENDAHULUAN}

Pendidikan sangat perlu dikembangkan dari berbagai bidang ilmu pengetahuan. Pendidikan yang berkualitas dapat meningkatkan kecerdasan suatu bangsa. Pendidikan merupakan bagian penting dari proses pembangunan nasional yang ikut meningkatkan pertumbuhan ekonomi suatu negara. Maka dari itu lembaga pendidikan sekolah dapat dikatakan bermutu dan memiliki peran aktif dalam mencerdasakan kehidupan bangsa.

Salah satu lembaga pendidikan yang ada di Indonesia adalah Sekolah Menengah Atas/ Sekolah Menengah Kejuruan (SMA/SMK) Yayasan Abdi Karya (YADIKA). YADIKA didirikan pada tanggal 14 Februari tahun 1976 oleh DR. Sutan Raja Darianus Lungguk Sitorus dan Ny. Luceria Siagian B.Sc keduanya adalah swasta bertempat tinggal di Jakarta. Aktivitas awal YADIKA adalah penyelenggaraan Bidang Kesehatan dengan mendirikan Rumah Sakit Bersalin di jalan Ciputat Raya Jakarta Selatan pada tahun 1976. Tahun 1978 YADIKA menyelenggarakan Bidang Pendidikan dengan mendirikan SMP Yadika 1 di Tanjung Duren Jakarta. Bidang Pendidikan YADIKA sejak tahun 1978 sampai saat ini telah menyelenggarakan 74 unit sekolah dan satu Perguruan Tinggi di 9 Propinsi mulai dari Taman Kanak-Kanak sampai dengan Perguruan Tinggi. Adapun objek penelitian ini adalah SMA/SMK YADIKA Tanjung Duren Jakarta Barat.

Hasil pengamatan dan observasi peneliti, terdapat beberapa permasalahan yang terjadi yang berkaitan dengan kepemimpinan, kompensasi dan disiplin kerja terhadap kinerja guru yang perlu diperhatikan oleh lembaga pendidikan SMA/SMK YADIKA Tanjung Duren Jakarta, dalam memberikan kenyamanan para guru untuk melaksanakan tanggung jawab yang diberikan.

Berdasarkan fenomena masalah yang ada pada lembaga maka peneliti tertarik untuk melakukan penelitian dengan judul: Analisis Kepemimpinan, Kompensasi Terhadap Kinerja Guru Dan Disiplin Kerja Sebagai Variabel Intervening di SMA/SMK Yadika Tanjung Duren Jakarta. 
Berdasarkan uraian latar belakang di atas maka dapat dirumuskan yang menjadi analisis masalah penelitian sebagai berikut:

1. Apakah terdapat pengaruh kepemimpinan terhadap disiplin kerja guru di SMA/SMK YADIKA Tanjung Duren Jakarta?

2. Apakah terdapat pengaruh kompensasi terhadap disiplin kerja di SMA/SMK YADIKA Tanjung Duren Jakarta?

3. Apakah terdapat pengaruh kepemimpinan dan kompensasi terhadap disiplin kerja di SMA/SMK YADIKA Tanjung Duren Jakarta?

4. Apakah terdapat pengaruh disiplin kerja terhadap kinerja guru SMA/SMK YADIKA Tanjung Duren Jakarta?

5. Apakah terdapat pengaruh kepemimpinan terhadap kinerja guru di SMA/SMK YADIKA Tanjung Duren Jakarta?

6. Apakah terdapat pengaruh kompensasi terhadap kinerja guru di SMA/SMK YADIKA Tanjung Duren Jakarta?

Adapun tujuan dilakukan penelitian ini adalah untuk mengetahui dan menganalisis ada atau tidak pengaruh antara pengaruh kepemimpinan, kompensasi (variable bebas) terhadap kinerja guru (variabel terikat) melalui disiplin kerja (variabel intervening) dengan kegunaan penelitian sebagai berikut:

1. Bagi SMA/SMK YADIKA Tanjung Duren Jakarta

Hasil penelitian ini dapat memberikan masukan sebagai bahan pertimbangan berkaitan dengan pengaruh kepemimpinan, kompensasi terhadap kinerja guru melalui disiplin kerja sebagai variabel intervening.

2. Bagi Kepala Sekolah

Hasil penelitian ini diharapkan dapat memperbaiki dan meningkatkan manajemen sekolah dan kondisi pelaksanaan pendidikan di SMA/SMK YADIKA Tanjung Duren Jakarta.

3. Bagi Guru

Hasil penelitian ini diharapkan bermanfaat bagi guru SMA/SMK YADIKA Tanjung Duren Jakarta sebagai bahan pembelajaran, diaplikasikan dan mengembangkan profesionalitas guru sehingga guru mampu menilai dan memperbaiki pembelajaran yang dikelolanya, dan menambah kepustakaan serta melengkapi penelitian mengenai pengaruh kepemimpinan, kompensasi terhadap kinerja guru melalui disiplin kerja sebagai variabel intervening.

4. Bagi Siswa

Hasil penelitian ini diharapkan dapat menjadi model bagi siswa bahwa pihak Kepala Sekolah dan guru memberikan perhatian khusus terhadap hasil belajar siswa, serta memperbaiki belajar siswa sehingga hasil belajar siswa diharapkan akan meningkat.

5. Bagi Peneliti Lain

Hasil penelitian ini diharapkan dapat menjadi tambahan rujukan bagi penelitian selanjutnya dan sebagai pertimbangan bagi organisasi yang menghadapi masalah serupa.

\section{LANDASAN TEORI}

\section{Kinerja Guru}

Menurut Supardi (2014:54) kinerja guru merupakan kemampuan seorang guru dalam melaksanakan tugas pembelajaran dan bertanggung jawab atas peserta didik dibawah bimbingannya dengan meningkatkan prestasi belajar peserta didik. Menurut Susanto (2012:52) kinerja guru merupakan perwujudan dari kemampuan dalam bentuk karya nyata, hasil kerja dan tanggung jawab dalam melaksanakan amanah, profesi yang diembannya dengan moral yang tinggi.

Berdasarkan definisi menurut para ahli di atas, maka peneliti mendefinisikan kinerja guru adalah hasil pekerjaan atau prestasi kerja yang dilakukan oleh seorang guru berdasarkan kemampuan dan kualitas kerja dengan mengelola kegiatan belajar mengajar meliputi; 
pelaksanaan, pengorganisasian, perencanaan, dan kontroling pembelajaran dan membina hubungan antar pribadi (interpersonal) dengan siswanya.

\section{Kepemimpinan}

Menurut Bangun (2012:337) bahwa kepemimpinan adalah proses pisikologis dalam menerima tanggung jawab tugas, diri sendiri, dan nasib orang lain. Handoko (2013:292) mengatakan bahwa kepemimpinan merupakan kemampuan yang dipunyai seseorang untuk mempengaruhi orang-orang lain agar bekerja mencapai tujuan dan sasaran.

Berdasarkan definisi di atas, peneliti mendefinsikan kepemimpinan adalah kemampuan seseorang atau sekelompok orang mempengaruhi pihak lain dan bertanggung jawab atas suatu kelompok melalui komunikasi langsung maupun tidak langsung dengan maksud menggerakan orang lain untuk mencapai tujuan.

\section{Kompensasi}

Menurut Sinambela (2016:220) mendefinisikan kompensasi adalah total dari semua penghargaan yang diberikan kepada pegawai sebagai imbalan atas jasa mereka berikan kepada organisasi. Menurut Bangun (2012:255) kompensasi adalah imbalan yang dibayarkan kepada karyawan atas jasa yang mereka sumbangkan pada pekerjaannya.

Berdasarkan definisi menurut para ahli di atas, maka peneliti mendefinisikan kompensasi adalah semua pendapatan yang berbentuk uang, barang langsung atau tidak langsung yang diterima pekerja atau karyawan sebagai imbalan atas jasa yang diberikan kepada perusahaan.

\section{Disiplin Kerja}

Menurut Hasibuan (2013:194) disiplin kerja adalah kesadaran dan kerelaan seseorang dalam mentaati semua peraturan perusahaan dan norma-norma sosial yang berlaku. Menurut Sinambela (2016:335), disiplin kerja adalah kemampuan kerja seseorang untuk secara teratur, tekun secara terus-menerus dan bekerja sesuai dengan aturan-aturan berlaku dengan tidak melanggar aturan-aturan yang sudah ditetapkan.

Berdasarkan definisi menurut para ahli di atas, maka peneliti mendefinisikan disiplin kerja adalah suatu sikap menghormati, menghargai, patuh dan taat pada peraturan-peraturan yang berlaku, baik yang tertulis maupun yang tidak tertulis serta sanggup menjalankan serta tidak mengelak menerima sanksi bila melanggar tugas serta wewenang yang diberikan.

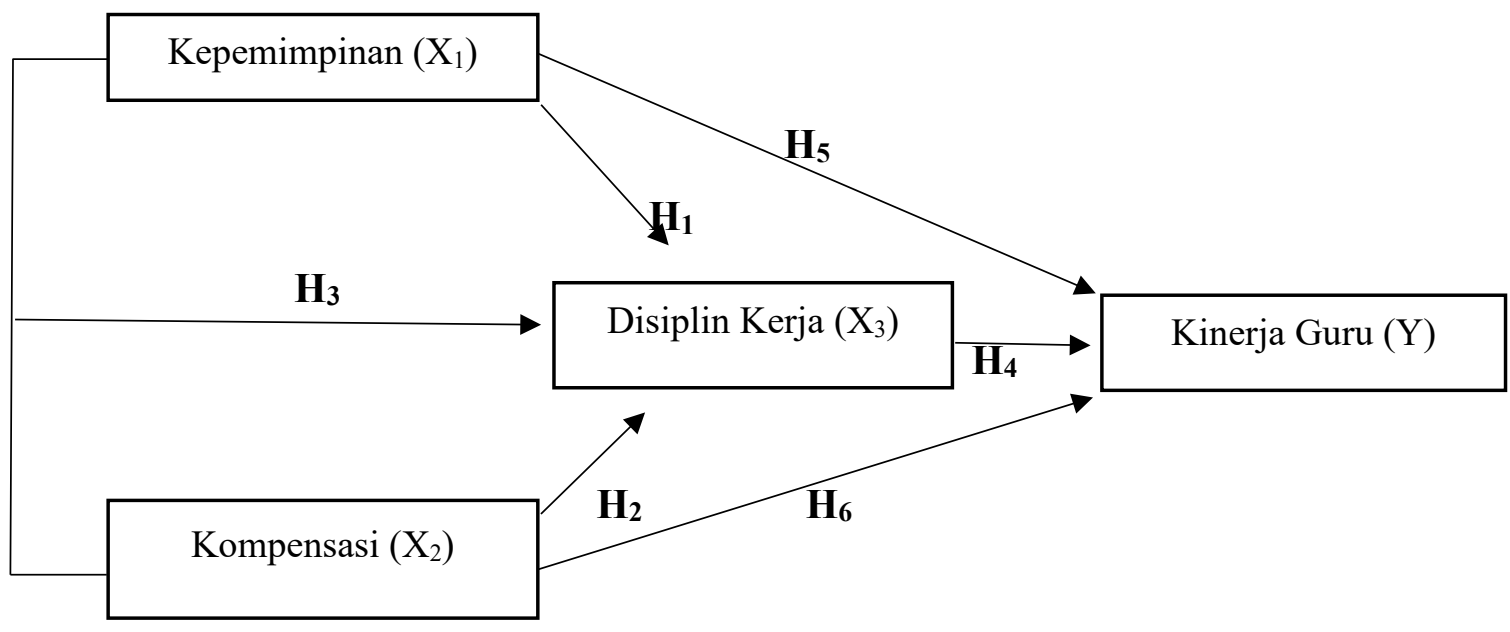

\section{Gambar 1: Kerangka Pemikiran}

\section{Hipotesis}

Berdasarkan kerangka pemikiran di atas, maka hipotesis dari penelitian ini adalah:

1. $\mathrm{Ho}_{1}$ : Diduga kepemimpinan tidak berpengaruh langsung terhadap disiplin kerja.

$\mathrm{Ha}_{1}$ : Diduga kepemimpinan berpengaruh langsung terhadap disiplin kerja. 
2. $\mathrm{Ho}_{2}$ : Diduga kompensasi tidak berpengaruh langsung terhadap disiplin kerja.

$\mathrm{Ha}_{2}$ : Diduga kompensasi berpengaruh langsung signifikan terhadap disiplin kerja.

3. $\mathrm{Ho}_{3}$ : Diduga kepemimpinan dan kompensasi tidak berpengaruh terhadap disiplin kerja.

$\mathrm{Ha}_{3}$ : Diduga kepemimpian dan kompensasi berpengaruh terhadap disiplin kerja.

4. Ho4: Diduga disiplin kerja tidak berpengaruh langsung terhadap kinerja guru.

$\mathrm{Ha}_{4}$ : Diduga disiplin kerja berpengaruh langsung terhadap kinerja karyawan.

5. Ho5: Diduga kepemimpinan tidak berpengaruh langsung terhadap kinerja guru.

Has: Diduga kepemimpian berpengaruh langsung terhadap kinerja guru.

6. $\mathrm{Ho}_{6}$ : Diduga kompensasi tidak berpengaruh simultan dan signifikan terhadap kinerja guru.

$\mathrm{Ha}_{6}$ : Diduga kompensasi berpengaruh simultan dan signifikan terhadap kinerja guru.

\section{METODOLOGI PENELITIAN}

Berdasarkan kerangka konseptual yang telah dijelaskan sebelumnya, maka teknik analisis data (metode kuantitatif) yang digunakan untuk menguji hipotesis penelitian adalah metode analisis jalur (Path Analysis). Analisis jalur merupakan perluasan dari analisis regresi linier berganda. Diagram jalur dapat digunakan untuk menghitung pengaruh langsung dan tidak langsung dari variabel eksogen terhadap suatu variabel endogen. Pengaruh-pengaruh itu tercermin dalam koefisien jalur, di mana secara matematik analisis jalur mengikuti model struktural.

Langkah pertama dalam analisis jalur adalah menerjemahkan hipotesis penelitian yang bentuknya proporsional ke dalam bentuk diagram. Diagram yang digunakan dalam analisis jalur disebut diagram jalur dan bentuknya ditentukan oleh preposisi teoritik yang berasal dari kerangka berpikir tertentu. Untuk menyederhanakan lambang, hanya digunakan dua lambang saja yaitu $\mathrm{X}$ dan $\varepsilon$ yang selanjutnya dinyatakan dengan $\left(\mathrm{X}_{1}, \mathrm{X}_{2}, \ldots, \mathrm{X}_{\mathrm{n}} \mathrm{nXXX}\right)$ terdiri dari variabel eksogen (exogenous variable) yang merupakan variabel penyebab dan variabel endogen (endogenous variable) sebagai variabel akibat. Sedangkan faktor-faktor lain yang merupakan variabel yang tidak sengaja diukur disebut implisit variabel (implisite variable) dilambangkan dengan yang dibedakan oleh yang selanjutnya disebut variabel galat (Retherford dalam Ghozali, 2008: 221).

\section{Skala Pengukuran Data}

Penelitian yang dilakukan selama tiga bulan mulai dari bulan Mei sampai dengan Juli, telah ditetapkan secara spesifik oleh peneliti, skala pengukuran sebagai alat ukur yang digunakan untuk mengkuantifikasi informasi yang diberikan oleh responden jika mereka diharuskan menjawab pertanyaan-pertanyaan yang sudah dirumuskan dalam suatu kuesioner. Teknik skala pengukuran yang peneliti gunakan dalam penelitian ini yaitu metode skala likert. Menurut Sugiyono (2013:136), skala likert merupakan skala yang digunakan untuk mengukur sikap, pendapat, dan persepsi seseorang atau sekelompok orang tentang fenomena sosial.

\section{Populasi dan Sampel}

Populasi merupakan wilayah generalisasi yang terdiri atas obyek/subyek yang mempunyai kualitas dan karakteristik tertentu yang ditetapkan oleh peneliti untuk dipelajari dan kemudian ditarik kesimpulannya, Sugiyono (2013:132). Populasi dalam penelitian ini guru SMA/SMK YADIKA Tanjung Duren Jakarta berjumlah 85 orang. Sementara sampel menurut Sugiyono (2013:120) merupakan bagian dari jumlah dan karakteristik yang dimiliki oleh populasi tersebut. Peneliti menggunakan teknik sampling dalam penentuan sampel sedangkan untuk menentukan sampel yang digunakan dalam penelitian ini menggunakan metode sensus, dimana semua populasi dijadikan sampel yaitu 85 orang. 


\section{Uji Validitas}

Uji validitas yang dimaksudkan untuk memastikan seberapa baik suatu instrumen mengukur konsep yang seharusnya diukur, menurut Sugiyono (2015:121). Dengan signifikan 0,05 dan nilai $\mathrm{k}$ (variabel independen) $=3$, untuk mengetahui perbedaan itu signifikan atau tidak maka nilai r-hitung tersebut perlu dibandingkan dengan nilai r-tabel. Untuk sampel sebanyak 85 responden didapatkan nilai $r$ tabel 0,213 menentukan $r$ tabel dapat dilihat pada tabel statistik pada signifikan 0,05. Dengan derajat kebebasan $\mathrm{df}=\mathrm{n}-\mathrm{k}$ atau 85-2 $=83$ diperoleh $\mathrm{r}$ tabel 0,213. Berdasarkan hasil pengujian validitas, diketahui bahwa nilai r-hitung dari semua indikator variabel lebih besar dari r-tabel $(0,213)$. Oleh karena semua indikator dalam penelitian ini adalah valid.

\section{Uji Reliabilitas}

Menguji reliabilitas kuesioner menggunakan rumus cronbach alpha dengan nilai 0,6 dengan asumsi bahwa daftar pertanyaan yang diuji akan dikatakan reliabel bila nilai Cronbach Alpha $>0,6$. Maka seluruh pernyataan berkaitan dengan variabel independen dan variabel dependen dalam kuesioner dikatakan reliabel. Hal ini dapat dilihat dari nilai Cronbach's Alpha kepemimpinan sebesar 0,931, kompensasi sebesar 0,923, disiplin kerja sebesar 0, 891, dan kinerja guru sebesar dari 0,901 , dengan kata lain seluruh pertanyaan pada penelitian ini memiliki tingkat keandalan yang baik dan dapat digunakan dalam analisis pada penelitian ini.

\section{Uji Normalitas}

Tabel 1

Hasil Asymptotic Signifikan

\begin{tabular}{|c|c|c|c|c|c|}
\hline & & Kepemimpinan & Kompensasi & $\begin{array}{l}\text { Disiplin_ } \\
\text { Kerja }\end{array}$ & $\begin{array}{l}\text { Kinerja_ } \\
\text { Guru }\end{array}$ \\
\hline $\begin{array}{l}\text { N } \\
\text { Normal } \\
\text { Parameters., } \\
\text { Most Extreme } \\
\text { Differences } \\
\text { Test Statistic } \\
\text { Asymp. Sig. (2-tailed) }\end{array}$ & $\begin{array}{l}\text { Mean } \\
\text { Std. } \\
\text { Deviation } \\
\text { Absolute } \\
\text { Positive } \\
\text { Negative }\end{array}$ & $\begin{array}{l}85 \\
79.76 \\
10.040 \\
.095 \\
.095 \\
-.095 \\
.095 \\
.056^{c} \\
\end{array}$ & $\begin{array}{l}85 \\
80.24 \\
9.695 \\
.095 \\
.080 \\
-.095 \\
.095 \\
.058^{c} \\
\end{array}$ & $\begin{array}{l}85 \\
79.21 \\
8.669 \\
.096 \\
.096 \\
-.093 \\
.096 \\
.052^{c}\end{array}$ & $\begin{array}{l}85 \\
79.59 \\
9.019 \\
.094 \\
.094 \\
-.093 \\
.094 \\
.062^{c} \\
\end{array}$ \\
\hline
\end{tabular}

Dari tabel di atas diperoleh hasil Asymptotic Signifikan (2-tailed). Asymptotic Signifikan merupakan pengujian nilai probabilitas atau p-value untuk memastikan bahwa disitiribusi teramati tidak menyimpang secara signifikan dari disitribusi yang diharapkan di kedua ujung twotailed distribusi. Untuk variabel kepemimpinan $\left(\mathrm{X}_{1}\right)=0,056>0,05$, kompensasi $\left(\mathrm{X}_{2}\right)=0,058>$ 0.05 , disiplin kerja $\left(\mathrm{X}_{3}\right)=0,052>0,05$ dan kinerja guru $(\mathrm{Y})=0,062>0,05$, maka dapat disimpulkan data yang diambil dari populasi terdistribusi normal.

Kemudian jika data menyebar di sekitar garis diagonal dan mengikuti arah garis diagonal atau grafik histogram menunjukkan pola distribusi normal, maka model regresi memenuhi asumsi normalitas. Tapi jika data menyebar jauh dari garis diagonal dan tidak mengikuti arah garis diagonal atau grafik histogram tidak menunjukkan pola distribusi normal, maka model regresi memenuhi asumsi. 


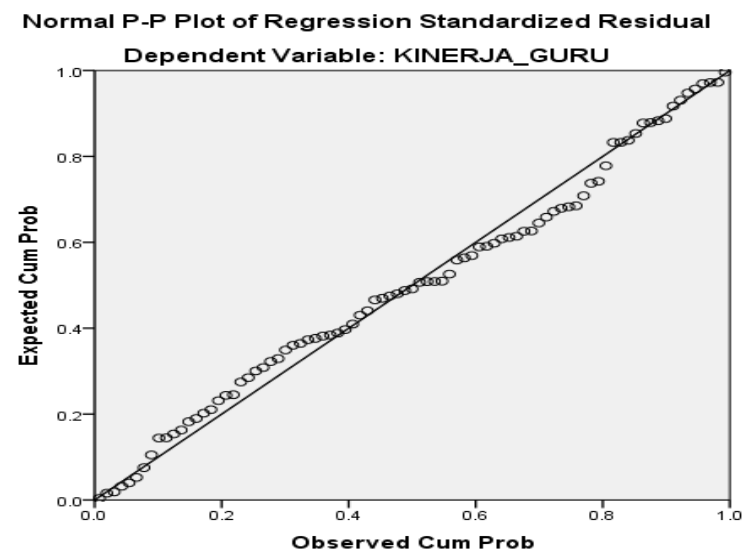

Gambar 2: Pola Distribusi Normal

Dari analisis kurva menunjukkan model regresi memenuhi asumsi normalitas. Hal ini dapat dilihat bahwa data menyebar di sekitar garis diagonal/menyebar mengikuti garis diagonal dan mengikuti model regresi sehingga dapat disimpulkan bahwa data yang diolah merupakan data yang berdistribusi normal sehingga uji normalitas terpenuhi.

\section{Uji Heteroskedastisitas}

Menurut Ghozali (2013:134) uji ini bertujuan untuk menguji apakah dalam sebuah model regresi terjadi ketidaksamaan varians dari residual. Jika varians satu pengamatan ke pengamatan yang lain tetap disebut homoskedastisitas dan jika varians berbeda, disebut heterokedastisitas. Model regresi yang baik adalah tidak terjadi heterokedastisitas. Untuk mendeteksi ada tidaknya heterokedastisitas dapat digunakan metode grafik scatterplot. Apabila pada gambar menunjukkan bahwa titik-titik menyebar secara acak serta tersebar baik di atas maupun di bawah angka 0 pada sumbu Y, maka dapat disimpulkan tidak terjadi adanya heterokedastisitas pada model regresi.

\section{Uji T (Uji Parsial)}

\section{Tabel 2 \\ Hasil Uji Parsial}

\begin{tabular}{|c|c|c|c|c|c|c|}
\hline \multicolumn{7}{|c|}{ Coefficients ${ }^{2}$} \\
\hline \multirow{2}{*}{\multicolumn{2}{|c|}{ Model }} & \multicolumn{2}{|c|}{$\begin{array}{l}\text { Unstandardized } \\
\text { Coefficients }\end{array}$} & \multirow{2}{*}{$\begin{array}{l}\text { Standardized } \\
\text { Coefficients } \\
\text { Beta }\end{array}$} & \multirow[b]{2}{*}{$t$} & \multirow[b]{2}{*}{ Sig. } \\
\hline & & $\mathrm{B}$ & Std. Error & & & \\
\hline & (Constant) & 38.219 & 9.782 & & 3.907 & .000 \\
\hline & Kepemimpinan & .473 & .083 & .526 & 5.663 & .000 \\
\hline & Kompensasi & -.339 & .194 & -.364 & -1.748 & .084 \\
\hline & Disiplin_Kerja & 390 & .217 & .375 & 1.797 & .076 \\
\hline
\end{tabular}

Untuk mengetahui t tabel dengan sampel 85 yaitu: df $-4=81$, maka diperoleh $\mathrm{t}$ tabel sebesar 1,663. Berdasarkan tabel di atas dapat disimpulkan bahwa:

a. Variabel kepemimpinan nilai $t_{\text {hitung }}>t_{\text {tabel }}$ maka Ho ditolak, maka ada pengaruh signifikan.

b. Variabel kompensasi nilai $t_{\text {hitung }}>t_{\text {tabel }}$ maka Ho ditolak, maka ada pengaruh negatif.

c. Variabel disiplin kerja nilai $t_{\text {hitung }}>t_{\text {tabel }}$ maka Ho ditolak, maka ada pengaruh signifikan. 


\section{Uji F (Uji Simultan)}

Tabel 3

Hasil Uji Simultan

\begin{tabular}{|c|c|c|c|c|c|}
\hline \multicolumn{6}{|c|}{ ANOVA $^{2}$} \\
\hline Model & Sum of Squares & Df & Mean Square & $\mathrm{F}$ & Sig. \\
\hline $\begin{array}{ll}1 \text { Regression } \\
\text { Residual } \\
\text { Total }\end{array}$ & $\begin{array}{l}2086.172 \\
4746.416 \\
6832.588 \\
\end{array}$ & $\begin{array}{l}3 \\
81 \\
84\end{array}$ & $\begin{array}{l}695.391 \\
58.598\end{array}$ & 11.867 & $.000^{b}$ \\
\hline
\end{tabular}

a. Dependent Variable: Kinerja_Guru

b. Predictors: (Constant), Disiplin_Kerja, Kepemimpinan, Kompensasi

Dari tabel di atas menunjukan bahwa nilai $\mathrm{F}_{\text {hitung }}$ sebesar 11.867. Sementara itu nilai $\mathrm{F}_{\text {tabel }}$ yang dilihat pada tabel nilai-nilai untuk distribusi $F$ adalah 2,48. Dengan demikian maka dapat dikatakan bahwa nilai $F_{\text {hitung }}=11,867>$ dari $F_{\text {tabel }}=2,48$. Ini berarti bahwa variabel independen yang terdiri dari kepemimpinan, kompensasi dan disiplin kerja berpengaruh secara simultan terhadap variabel kinerja guru SMA/SMK YADIKA Tanjung Duren Jakarta.

\section{Uji Analisis Jalur}

Tabel 4

Hasil Analisis Struktur 1

Model Summary

\begin{tabular}{|c|c|c|c|c|c|c|c|c|c|}
\hline \multirow[b]{2}{*}{ Model } & \multirow[b]{2}{*}{$R$} & \multirow[b]{2}{*}{\begin{tabular}{|l}
$R$ \\
Square
\end{tabular}} & \multirow[b]{2}{*}{$\begin{array}{l}\text { Adjusted } \\
\text { R Square }\end{array}$} & \multirow[b]{2}{*}{$\begin{array}{l}\text { Std. Error of } \\
\text { the Estimate }\end{array}$} & \multicolumn{5}{|c|}{ Change Statistics } \\
\hline & & & & & $\begin{array}{l}\text { R Square } \\
\text { Change }\end{array}$ & \begin{tabular}{|l} 
F \\
Change
\end{tabular} & df1 & $\mathrm{df} 2$ & $\begin{array}{l}\text { Sig. } F \\
\text { Change }\end{array}$ \\
\hline 1 & $.896^{a}$ & .803 & .798 & 3.897 & .803 & 166.819 & 2 & 82 & .000 \\
\hline 2 & $.896^{\mathrm{b}}$ & .803 & .800 & 3.874 & .000 & .015 & 1 & 82 & .902 \\
\hline
\end{tabular}

Berdasarkan hasil analisis dari tabel di atas koefisien determinasi untuk model $1\left(\mathrm{R}^{2}\right)$ sebesar 0,803 dan model $2\left(\mathrm{R}^{2}\right)$ sebesar 0,803 . Maka besarnya pengaruh variabel lain di luar model (error) terhadap variabel disiplin kerja $\left(\mathrm{X}_{3}\right)$ adalah $\varepsilon_{1}=1-\mathrm{R}^{2}=1-0,803=0,197 \approx 0,20$.

\section{Tabel 5}

\section{ANOVA}

ANOVA $^{\mathrm{a}}$

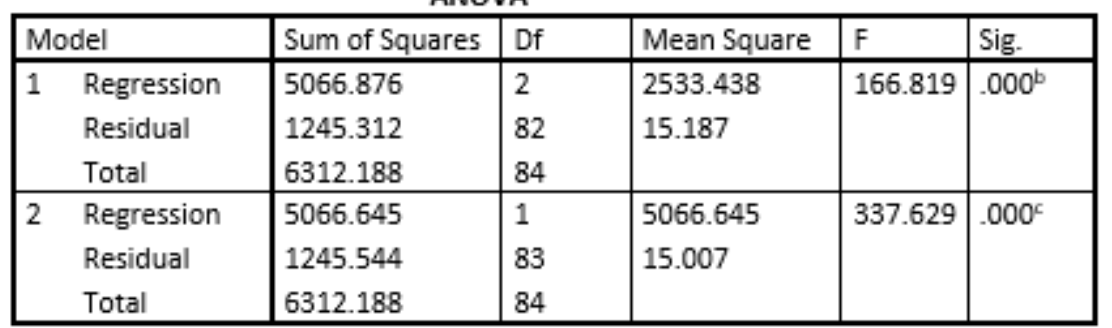

a. Dependent Variable: Disiplin_Kerja

b. Predictors: (Constant), Kompensasi, Kepemimpinan

c. Predictors: (Constant), Kompensasi

Berdasarkan hasil analisis pada tabel di atas, model 1 diperoleh $\mathrm{Fo}=166,819 ; \mathrm{db} 1=2$; $\mathrm{db} 2=82 ; \mathrm{p}$-value $=0,000<0,05$ dan model $2 \mathrm{Fo}=337,629 ; \mathrm{db} 1=1 ; \mathrm{db} 2=83 ; \mathrm{p}$-value $=$ $0,000<0,05$ atau $\mathrm{H}_{0}$ ditolak, dengan demikian secara simultan variabel kepemimpinan $\left(\mathrm{X}_{1}\right)$ dan 
variabel kompensasi $\left(\mathrm{X}_{2}\right)$, berpengaruh terhadap variabel disiplin kerja $\left(\mathrm{X}_{3}\right)$ guru SMA/SMK YADIKA Tanjung Duren Jakarta.

Tabel 6

Standar Koefisien Struktur 1

\begin{tabular}{|c|c|c|c|c|c|}
\hline \multirow[b]{3}{*}{ Model } & & Coefficients $^{\mathrm{a}}$ & & \multirow[b]{3}{*}{$T$} & \multirow[b]{3}{*}{ Sig. } \\
\hline & \multicolumn{2}{|c|}{ Unstandardized Coefficients } & \begin{tabular}{|l} 
Standardized \\
Coefficients
\end{tabular} & & \\
\hline & $B$ & Std. Error & Beta & & \\
\hline \multirow{3}{*}{$\begin{array}{ll}1 \text { (Constant) } \\
\text { Kepemimpina } \\
n \\
\text { Kompensasi } \\
\end{array}$} & 14.553 & 4.714 & & 3.087 & .003 \\
\hline & .005 & .042 & .006 & .124 & .902 \\
\hline & .801 & .044 & .895 & 18.197 & .000 \\
\hline \multirow{2}{*}{$\begin{array}{ll}2 & \text { (Constant) } \\
& \text { Kompensasi } \\
\end{array}$} & 14.937 & 3.523 & & 4.240 & .000 \\
\hline & .801 & .044 & .896 & 18.375 & .000 \\
\hline
\end{tabular}

a. Dependent Variable: Disiplin_Kerja

Metode backward merupakan metode regresi yang baik, karena dalam metode ini dijelaskan prilaku variabel respon dengan lebih baik memilih variabel penjelas. Diperoleh dua model hasil pengolahan data, yaitu model 1 dan model 2. Koefisien jalur diperoleh pada kolom Beta (Standardized Coefficient), yaitu $\left(\mathrm{P}_{31}\right)=0,005$. Dari tabel Coefficient model 1, diperoleh berturut-turut:

a. $\mathrm{P}_{31}=0,006 ; \mathrm{t}_{0}=0,124, \mathrm{p}$-value $=0,902 / 2=0,451>0,05$, atau $\mathrm{H}_{0}$ diterima, yang berarti tidak terdapat pengaruh langsung antara kepemimpinan $\left(\mathrm{X}_{1}\right)$ terhadap disiplin kerja $\left(\mathrm{X}_{3}\right)$ guru SMA/SMK YADIKA Tanjung Duren Jakarta.

b. $\quad \mathrm{P}_{32}=0,895 ; \mathrm{t}_{0}=18,197, \mathrm{p}$-value $=0,000 / 2=0,000<0,05$, atau $\mathrm{H}_{0}$ ditolak, yang berarti kompensasi $\left(\mathrm{X}_{2}\right)$ mempunyai pengaruh langsung positif terhadap disiplin kerja $\left(\mathrm{X}_{3}\right)$ guru SMA/SMK YADIKA Tanjung Duren Jakarta.

Dari analisis ini terlihat bahwa ternyata kofisien jalur $\left(\mathrm{P}_{31}\right)$ tidak signifikan, maka model perlu diperbaiki dengan mengeluarkan $\mathrm{X}_{1}$ dari model (trimming). Maka hasilnya langsung dapat diperoleh atau dibaca pada tabel coefficients model 2. Sehingga koefisien jalur setelah trimming adalah $\mathrm{P}_{32}=0,896$; dengan $\mathrm{t}_{0}=18,375$, dan $\mathrm{p}$-value $=0,000<0,05$, atau $\mathrm{H}_{0}$ ditolak, dengan demikian, setelah trimming kompensasi $\left(\mathrm{X}_{2}\right)$ mempunyai pengaruh langsung positif terhadap disiplin kerja $\left(\mathrm{X}_{3}\right)$ guru SMA/SMK YADIKA Tanjung Duren Jakarta.

\section{Tabel 7}

Hasil Analisis Struktur 2

Model Summary

\begin{tabular}{|c|c|c|c|c|c|c|c|c|c|}
\hline \multirow[b]{2}{*}{ Model } & \multirow[b]{2}{*}{$R$} & \multirow[b]{2}{*}{$\begin{array}{l}R \\
\text { Square }\end{array}$} & \multirow[b]{2}{*}{$\begin{array}{l}\text { Adjusted } \\
\text { R Square }\end{array}$} & \multirow[b]{2}{*}{$\begin{array}{l}\text { Std. Error of } \\
\text { the Estimate }\end{array}$} & \multicolumn{5}{|c|}{ Change Statistics } \\
\hline & & & & & $\begin{array}{l}\text { R Square } \\
\text { Change }\end{array}$ & $\begin{array}{l}\text { F } \\
\text { Change }\end{array}$ & df1 & df2 & $\begin{array}{l}\text { Sig. } \quad F \\
\text { Change }\end{array}$ \\
\hline 1 & $.553^{\mathrm{a}}$ & .305 & .280 & 7.655 & .305 & 11.867 & 3 & 81 & .000 \\
\hline
\end{tabular}

Tampak bahwa koefisien determinasi untuk model $1\left(\mathrm{R}^{2}\right)$ sebesar 0,305 , maka besarnya pengaruh variabel lain di luar model (error) terhadap variabel kinerja guru (Y) adalah sebesar error model $2, \varepsilon_{2}=1-\mathrm{R}^{2}=1-0,305=0,695 \approx 0,69$. 
Tabel 8

Standar Koefisien Struktur 2

\begin{tabular}{|c|c|c|c|c|c|}
\hline \multirow[b]{3}{*}{ Model } & \multicolumn{3}{|c|}{ Coefficients $^{\mathrm{a}}$} & \multirow[b]{3}{*}{$\mathrm{T}$} & \multirow[b]{3}{*}{ Sig. } \\
\hline & \multicolumn{2}{|c|}{$\begin{array}{l}\text { Unstandardized } \\
\text { Coefficients }\end{array}$} & \multirow{2}{*}{$\begin{array}{l}\text { Standardized } \\
\text { Coefficients } \\
\text { Beta }\end{array}$} & & \\
\hline & B & Std. Error & & & \\
\hline 1 (Constant) & 38.219 & 9.782 & & 3.907 & .000 \\
\hline $\begin{array}{l}\text { Kepemimpina } \\
\mathrm{n}\end{array}$ & .473 & .083 & .526 & 5.663 & .000 \\
\hline Kompensasi & -.339 & .194 & -.364 & -1.748 & .084 \\
\hline Disiplin_Kerja & .390 & .217 & .375 & 1.797 & 076 \\
\hline
\end{tabular}

Dengan menggunakan metode Backward, diperoleh koefisien jalur yang ditunjukkan oleh kolom Standardized Coeficient (Beta). Hipotesis yang akan di uji adalah:
a) $\mathbf{H}_{0}: \mathbf{P}_{\mathbf{y} 1}$ b) $\mathbf{H}_{0}: \mathbf{P}_{\mathbf{y} 2}$
c) $\mathbf{H}_{0}: \mathbf{P}_{\mathbf{y} 3}$
$\mathbf{H}_{\mathbf{a}}: \mathbf{P}_{\mathbf{y}}$
$\mathbf{H}_{\mathbf{a}}: \mathbf{P}_{\mathbf{y} 2}$
$\mathbf{H}_{\mathrm{a}}: \mathbf{P}_{\mathbf{y} 3}$

Dari tabel Coefficient, diperoleh berturut-turut:

a. $\quad \mathrm{P}_{\mathrm{y} 1}=0,526 ; \mathrm{t}_{0}=5,663, \mathrm{p}$-value $=0,000 / 2=0,000<0,05, \mathrm{H}_{0}$ ditolak, yang berarti kepemimpinan $\left(\mathrm{X}_{1}\right)$ berpengaruh langsung positif terhadap kinerja guru $(\mathrm{Y})$.

b. $\mathrm{P}_{\mathrm{y} 2}=-0,364 ; \mathrm{t}_{0}=-1,748, \mathrm{p}$-value $=0,084 / 2=0,042<0,05, \mathrm{H}_{0}$ ditolak, yang berarti kompensasi $\left(\mathrm{X}_{2}\right)$ berpengaruh langsung negatif terhadap kinerja guru $(\mathrm{Y})$.

c. $\quad \mathrm{P}_{\mathrm{y} 3}=0,375 ; \mathrm{t}_{0}=1,797, \mathrm{p}$-value $=0,076 / 2=0,038<0,05, \mathrm{H}_{0}$ ditolak, yang berarti disiplin kerja $\left(\mathrm{X}_{3}\right)$ berpengaruh langsung positif terhadap kinerja guru $(\mathrm{Y})$.

Dengan demikian, berdasarkan hasil pengujian hipotesis, model kausal empiris $X_{1}, X_{2}$, terhadap $Y$ melalui $\mathrm{X}_{3}$, divisualkan sebagai berikut:

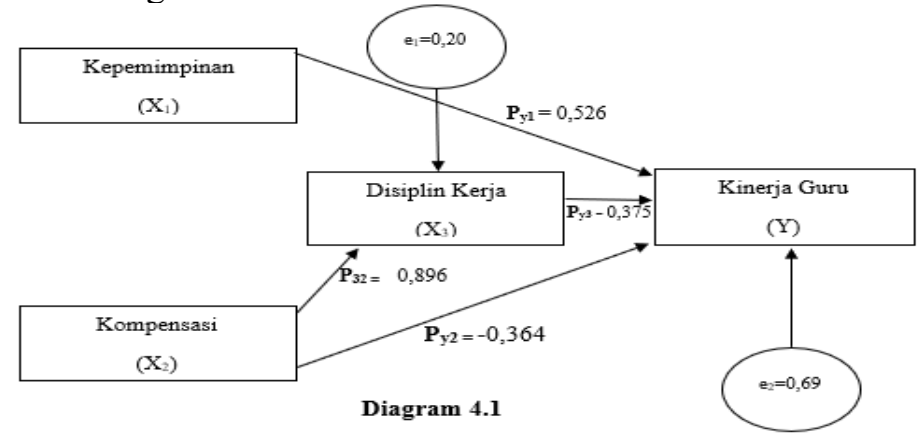

\section{Pembahasan}

\section{Pengaruh Kepemimpinan terhadap Disiplin Kerja}

Kepemimpinan tidak terdapat pengaruh langsung terhadap disiplin kerja. Hal ini dibuktikan pada uji hipotesis dimana nilai $t_{\text {hitung }} 0,124$ dan nilai $p$-value $=0,902 / 2=0,451>0,05$ $\mathrm{H}_{0}$ diterima, yang berarti kepemimpinan tidak berpengaruh langsung terhadap disiplin kerja. Penelitian ini sesuai dengan penelitian yang dilakukan oleh Emmy (2011) dengan judul "Pengaruh Kepemimpinan, Lingkungan Kerja, terhadap Kinerja Pegawai melalui Disiplin Kerja PTIIK Universitas Brawijaya". Bahwa variabel kepemimpinan tidak berpengaruh langsung terhadap disiplin kerja PTIIK Universitas Brawijaya.

\section{Pengaruh Kompensasi terhadap Disiplin Kerja}

Kompensasi berpengaruh langsung positif dan signifikan terhadap disiplin kerja. Hal ini dibuktikan oleh hasil pengujian hipotesis, dimana nilai $t_{\text {hitung }} 18,375$ dan nilai $\mathrm{p}$-value $=0,000 / 2=$ $0,000<0,05$, atau $\mathrm{H}_{0}$ ditolak, yang berarti kompensasi mempunyai pengaruh langsung positif dan signifikan terhadap disiplin kerja. Hasil penelitian ini sesuai dengan penelitian sebelumnya yang dilakukan oleh Adrian (2017) bahwa kompensasi mempunyai pengaruh langsung terhadap disiplin kerja yang positif pada PT. Trio Corporate Plastic (Tricopla). 


\section{Pengaruh Kepemimpinan dan Kompensasi terhadap Disiplin Kerja}

Berdasarkan hasil uji analisis, kepemimpinan dan kompensasi terhadap disiplin kerja, pada model 1 diperoleh $\mathrm{Fo}=166,819 ; \mathrm{db} 1=2 ; \mathrm{db} 2=82 ; \mathrm{p}$-value $=0,000<0,05$ dan model 2 $\mathrm{Fo}=337,629 ; \mathrm{db} 1=1 ; \mathrm{db} 2=83 ; \mathrm{p}$-value $=0,000<0,05$ atau $\mathrm{H}_{0}$ ditolak, dengan demikian secara simultan variabel kepemimpinan $\left(\mathrm{X}_{1}\right)$ dan variabel kompensasi $\left(\mathrm{X}_{2}\right)$, berpengaruh terhadap variabel disiplin kerja $\left(\mathrm{X}_{3}\right)$ guru SMA/SMK YADIKA Tanjung Duren Jakarta. Hasil penelitian ini didukung oleh penelitian sebelumnya yang dilakukan oleh Fildza at all (2016) yang berjudul Pengaruh Kepemimpinan dan Kompensasi terhadap Disiplin Kerja studi pada karyawan PT. BRI Syariah Kantor Cabang Malang. Bahwa pengaruh variabel kepemimpinan dan kompensasi berpengaruh signifikan secara simultan terhadap disiplin kerja dapat di terima.

\section{Pengaruh Disiplin Kerja terhadap Kinerja Guru}

Disiplin kerja berpengaruh langsung positif dan signifikan terhadap kinerja guru. Hal ini dibuktikan oleh hasil pengujian hipotesis, di mana nilai $t_{\text {hitung }}=1,797$, $\mathrm{p}$-value $=0,076 / 2=0,038<$ $0,05, \mathrm{H}_{0}$ ditolak, yang berarti terdapat pengaruh langsung Disiplin Kerja terhadap Kinerja Guru SMA/SMK YADIKA Tanjung Duren Jakarta. Penelitian ini sejalan dengan penelitian yang di lakukan oleh Daniel (2015): Pengaruh Kompensasi dan Disiplin Kerja terhadap Kinerja Karyawan Kantor PT. Keramik Diamond Industries. Bahwa disiplin kerja memberikan pengaruh yang signifikan terhadap kinerja karyawan PT. Keramik Diamond Industries.

\section{Pengaruh Kepemimpinan terhadap Kinerja Guru}

Kepemimpinan berpengaruh langsung positif dan signifikan terhadap kinerja guru. Hal ini dibuktikan oleh hasil pengujian hipotesis di mana nilai $t_{\text {hitung }}=5,663 \mathrm{p}$-value $=0,000 / 2=0,000$ $<0,05$ atau $\mathrm{H}_{0}$ ditolak, yang berarti kepemimpinan berpengaruh langsung positif terhadap kinerja guru SMA/SMK YADIKA Tanjung Duren Jakarta . Penelitian ini sejalan dengan penelitian yang di lakukan oleh Yuli (2015) dengan judul "Pengaruh Kepemimpinan dan Motivasi Kerja terhadap Kinerja Karyawan pada PT. Tunas Hijau Samarinda". Bahwa variabel Kepemimpinan berpengaruh positif dan signifikan terhadap kinerja karyawan pada PT. Tunas Hijau Samarinda.

\section{Pengaruh Kompensasi terhadap Kinerja Guru}

Kompensasi berpengaruh langsung negatif terhadap kinerja guru. Hal ini dibuktikan oleh hasil pengujian hipotesis diperoleh hasil $t_{\text {hitung }}=-1,748$, dan nilai $\mathrm{p}$-value $=0,084 / 2=0,042<0,05$ $\mathrm{H}_{0}$ ditolak, yang berarti kompensasi berpengaruh langsung negatif signifikan terhadap kinerja guru SMA/SMK YADIKA Tanjung Duren Jakarta. Penelitian ini sejalan dengan penelitian yang di lakukan oleh Budi (2014) yang berjudul "Analisis Pengaruh Kompensasi, Motivasi, Lingkungan kerja, dan Budaya Organisasi Terhadap Kinerja karyawan di Lingkungan Pegawai Kantor PDAM Boyolali” bahwa kompensasi berpengaruh negatif terhadap kinerja karyawan.

\section{PENUTUP}

Kesimpulan

1. Tidak terdapat pengaruh langsung variabel kepemimpinan $\left(X_{1}\right)$ terhadap disiplin kerja $\left(X_{3}\right)$ guru SMA/SMK YADIKA Tanjung Duren Jakarta.

2. Terdapat pengaruh langsung positif dan signifikan variabel kompensasi $\left(\mathrm{X}_{2}\right)$ terhadap disiplin kerja $\left(\mathrm{X}_{3}\right)$ guru SMA/SMK YADIKA Tanjung Duren Jakarta.

3. Terdapat pengaruh positif dan signifikan variabel kepemimpinan $\left(\mathrm{X}_{1}\right)$, kompensasi $\left(\mathrm{X}_{2}\right)$ terhadap disiplin kerja $\left(\mathrm{X}_{3}\right)$ guru SMA/SMK YADIKA Tanjung Duren Jakarta.

4. Terdapat pengaruh positif dan signifikan variabel disiplin kerja $\left(\mathrm{X}_{3}\right)$ terhadap kinerja guru (Y) guru SMA/SMK YADIKA Tanjung Duren Jakarta.

5. Terdapat pengaruh positif dan signifikan variabel kepemimpinan $\left(\mathrm{X}_{1}\right)$ terhadap kinerja guru (Y) SMA/SMK YADIKA Tanjung Duren Jakarta.

6. Terdapat pengaruh langsung negatif antara variabel kompensasi $\left(\mathrm{X}_{2}\right)$ terhadap kinerja guru (Y) guru SMA/SMK YADIKA Tanjung Duren Jakarta. 


\section{Saran}

Berdasarkan hasil penelitian dan kesimpulan yang telah dikemukakan di atas, maka saran yang dapat diberikan untuk:

1. YADIKA lebih memperhatikan kerjasama dengan Kepala Sekolah guna meningkatkan kinerja guru agar tercapai tujuan yang ditetapkan. Memperhatikan pemberian kompensasi kepada guru karena dengan pemberian kompensasi yang baik dan besar dapat meningkatkan disiplin kerja dan kinerja guru serta memberikan pelatihan pada guru SMA/SMK YADIKA Tanjung Duren Jakarta untuk meningkatkan kinerja guru dan produktivitas guru menjadi lebih baik lagi.

2. Kepala Sekolah hendaknya lebih memotivasi para guru untuk dapat meningkatkan kinerja, maka perlu adanya pengembangan melalui pendidikan dan pelatihan. Mampu menunjukan peran kepemimpinan dengan baik untuk menjalankan tanggung jawab secara cermat serta menanamkan rasa memiliki hubungan yang kuat kepada guru. Berperan aktif dalam meningkatkan kinerja guru baik dari unsur prilaku guru, ketepatan waktu, efesiensi pekerjaan, disiplin kerja, absensi atau tingkat kehadiran guru. Sehingga guru akan lebih berperan aktif dalam mencapai tujuan sekolah yang telah ditetapkan.

3. Guru diharapkan menumbuhkan motivasi berprestasi yang tinggi dan menciptakan sikap guru yang lebih baik lagi dalam segi disiplin kerja dan meningkatkan kinerja.

4. Siswa hendaknya lebih memperhatikan proses belajar mengajar, agar memahami materi yang diberikan oleh guru dan dicerna serta mengembakan motivasi belajar.

5. Peneliti selanjutnya diharapkan dapat digunakan sebagai salah satu sumber data untuk penelitian selanjutnya dan mengevaluasi pernyataan-pernyataan dalam kuesioner agar dapat mewakili secara tepat variabel yang hendak diukur.

\section{DAFTAR PUSTAKA}

Bangun, Wilson. 2012. Manajemen Sumber Daya Manusia, Erlangga, Jakarta.

Danim, Sudarwan. 2010. Profesionalisasi dan Etika Profesi Guru, Erlangga, Jakarta.

Ghozali, Imam. 2013. Aplikasi Analisis Multivariat dengan Program IBM SPSS 21. Edisi 7, Penerbit Universitas Diponegoro, Semarang.

Handoko, Hani. 2013. Manajemen Sumber Daya Manusia, Salemba, Empat, Jakarta.

Hasibuan, Malayu. S.P. 2014. Manajemen Sumber Daya Manusia (EdisiRevisi), Bumi Aksara, Jakarta.

Mangkunegara, Anwar Prabu. 2016. Manajemen Sumber Daya Manusia Perusahaan, Remaja Rosdakarya, Bandung.

Susanto, Ahmad. 2012, Manajemen Peningkatan Kinerja Guru, Salemba, Empat, Jakarta.

Singodimedjo. 2013. Pengembangan Sumber Daya Manusia, Rineka Cipta, Jakarta.

Sastrohadiwiryo, B Siswanto. 2016. Manajemen Tenaga Kerja Indonesia, Rineka Cipta, Jakarta.

Simammora. 2015. Manajemen Sumber Daya Manusia, Bumi Aksara, Jakarta.

Sinambella, Lijan. 2016. Manajemen Sumber Daya Manusia Membangun Tim Kerja Yang Solid Untuk Meningkatkan Kinerja, Bumi Aksara, Jakarta.

Sugiyono. 2015. Metode Penelitian Kuantitatif Kualitatif, dan R\&D. Alfabeta, Bandung.

Supardi. 2014. Kinerja Guru, Raja Grafindo Persada, Jakarta.

Sutrisno, Edy. 2010. Manajemen Sumber Daya Manusia, Salemba, Empat, Jakarta.

Tohardi, Ahmad. 2010. Manajemen Sumber Daya Manusia, Universitas Tanjung Pura, Mandar Maju, Bandung. 